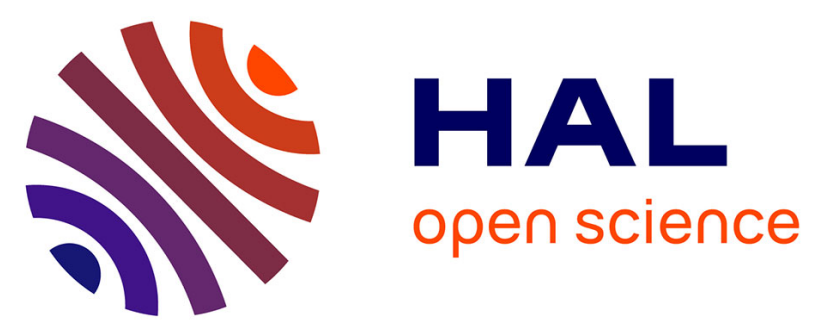

\title{
Photophysics, electronic structure and solar cell performance of a donor-acceptor poly(N-dodecyl-2,7-carbazole-alt-benzothiadiazole) copolymer
}

Aimilios Koutsoubelitis, Kostas Seintis, Dimitrios Tsikritzis, Jules Oriou, Cyril Brochon, Eric Cloutet, Georges Hadziioannou, Maria Vasilopoulou, Stella Kennou, Mihalis Fakis, et al.

\section{- To cite this version:}

Aimilios Koutsoubelitis, Kostas Seintis, Dimitrios Tsikritzis, Jules Oriou, Cyril Brochon, et al.. Photophysics, electronic structure and solar cell performance of a donor-acceptor poly(Ndodecyl-2,7-carbazole-alt-benzothiadiazole) copolymer. Organic Electronics, 2018, 59, pp.202-212. 10.1016/j.orgel.2018.04.047 . hal-01783553

\section{HAL Id: hal-01783553 https://hal.science/hal-01783553}

Submitted on 28 Aug 2020

HAL is a multi-disciplinary open access archive for the deposit and dissemination of scientific research documents, whether they are published or not. The documents may come from teaching and research institutions in France or abroad, or from public or private research centers.
L'archive ouverte pluridisciplinaire $\mathbf{H A L}$, est destinée au dépôt et à la diffusion de documents scientifiques de niveau recherche, publiés ou non, émanant des établissements d'enseignement et de recherche français ou étrangers, des laboratoires publics ou privés. 


\title{
Photophysics, Electronic Structure and Solar Cell Performance of a Donor-Acceptor Poly(N-dodecyl-2,7-carbazole-alt-benzothiadiazole) Copolymer
}

\author{
Aimilios Koutsoubelitis ${ }^{1}$, Kostas Seintis ${ }^{1}$, Dimitrios Tsikritzis ${ }^{2}$, \\ Jules Oriou ${ }^{3,4}$, Cyril Brochon ${ }^{3,4}$, Eric Cloutet ${ }^{3,4}$, Georges Hadziioannou ${ }^{3,4}$, \\ Maria Vasilopoulou ${ }^{5}$, Stella Kennou ${ }^{2}$, Mihalis Fakis ${ }^{1 *}$ \\ and Leonidas C. Palilis ${ }^{1 \text { ** }}$
}

${ }^{1}$ Department of Physics, University of Patras, 26500 Patras, Greece

${ }^{2}$ Department of Chemical Engineering, University of Patras, 26500 Patras, Greece

${ }^{3}$ Centre National de la Recherche Scientifique, Laboratoire de Chimie des Polymères Organiques, UMR 5629, Bordeaux INP, 16 Avenue Pey-Berland Pessac Cedex, F33607 France

${ }^{4}$ Université de Bordeaux, Laboratoire de Chimie des Polymères Organiques, UMR 5629, Bordeaux INP, Pessac Cedex, F-33607 France

${ }^{5}$ Institute of Nanoscience and Nanotechnology, National Center for Scientific Research, Demokritos, Agia Paraskevi, 15310 Athens, Greece

\section{AUTHOR INFORMATION \\ Corresponding Authors \\ *Email: fakis@ upatras.gr \\ E**ail: 1palilis@physics.upatras.gr}

\begin{abstract}
In this contribution, we investigate the optoelectronic properties of a donor-acceptor poly(N-Dodecyl-2,7-carbazole-alt-benzothiadiazole (CBZ-BT) copolymer in solutions and thin films, by a combination of complementary optical and electronic spectroscopy techniques including stationary absorption and fluorescence, femtosecond time-resolved and ultraviolet/x-ray photoelectron spectroscopy. Absorption spectroscopy revealed two bands at 322/338 and 445/475 nm for CBZ-BT in solutions/films attributed to the carbazole and benzothiadiazole groups respectively. Photoexcitation either to the absorption band of the carbazole or benzothiadiazole group led to a broad and structureless fluorescence spectrum due to large torsional disorder in the excited state, originating from intramolecular energy transfer between carbazole and benzothiadiazole. Time resolved spectroscopy in solutions reveals a transient red-shift of the emission spectrum within less than $5 \mathrm{ps}$ due to exciton migration and/or conformational relaxation of the polymer backbone. In films, this relaxation is faster accompanied by a quenching of the exciton lifetime.
\end{abstract}


Fluorescence depolarization in solutions follows the rate of spectral relaxation. In films, the overall depolarization is faster leading to a reduced limiting anisotropy, due to efficient energy transfer to adjacent chains with different polarization of the transition dipoles and increased disorder in the solid state. An almost complete quenching of the copolymer fluorescence, taking place on $\sim 150 \mathrm{fs}$, was observed upon blending with a fullerene PC70BM acceptor pointing to an efficient electron transfer. CBZ-BT shows a large solid-state ionization potential of $6.2 \mathrm{eV}$ and an electron affinity of $3.7 \mathrm{eV}$. Its potential as an electron donor in polymer solar cells (PSCs) was unveiled upon fabrication of relatively high open circuit voltage $(\sim 0.85$ V) but low power conversion efficiency $(\sim 1.7 \%)$ bulk-heterojunction single layer PSCs with PC70BM as electron acceptor.

\section{Introduction}

Since the discovery of organic photovoltaic (OPV) cells in the early 1990's [1,2], a new era in renewable energy applications has emerged. OPV technology has attracted significant interest because of their many advantages such as their compatibility with low cost roll-to-roll [3] or lithography-based [4] manufacturing processes and their easy and low cost fabrication [5-7]. Currently, the critical challenge for OPVs is to extend their long term stability combined with a high power conversion efficiency (PCE) of $15 \%$, a goal that has been recently approached by employing novel conjugated copolymers with improved optoelectronics properties, non-fullerene acceptors and more sophisticated tandem structures enabled by intelligent interfacial engineering and passivation [8-20]. Highly efficient organic solar cells utilize a solution-processed bulk-heterojunction (BHJ) structure, in which polymeric donor and fullerene acceptor molecules form nanoscale interpenetrating hole and electron transporting networks, respectively [5-7]. The open circuit voltage $\left(\mathrm{V}_{\mathrm{oc}}\right)$ of OPVs critically depends on the energy level offset between the HOMO level of the polymer and the LUMO level of the fullerene and is primarily limited by the rather low ionization potential of most conjugated polymers and interfacial, non-radiative, recombination. The short circuit current $\left(\mathrm{J}_{\mathrm{sc}}\right)$ is mainly limited by the narrow absorption range of most conjugated polymers and the donor:acceptor film morphology that needs to be optimized in order to maximize the interfacial area for efficient exciton dissociation and charge separation.

New donor-acceptor (D-A) copolymers may provide an efficient route for utilizing longer wavelength absorption as a result of intramolecular energy transfer from the donor to the acceptor unit [21,22]. Additionally, for higher $\mathrm{V}_{\mathrm{oc}}$ polymer solar cells (PSCs), there is a need for new polymer donor materials with larger ionization potentials that will enable stable cell operation in air. There are three main prerequisites for such an efficient donor (co)polymer in PSCs: enhance compatibility to allow uniform mixing with appropriate acceptors and stable film morphology, a large ionization potential (deep lying $\mathrm{HOMO},>5.5 \mathrm{eV}$ ) to increase both $\mathrm{V}_{\text {oc }}$ and cell 
stability against oxidation, a relatively small bandgap and a low electron affinity (high lying LUMO) to allow enhanced utilization of the solar spectrum and efficient, ultrafast, photoinduced electron transfer to fullerenes, respectively. A large variety of narrow band gap D-A copolymers have been constructed mainly by alternative electron-rich and electron-deficient units in the main chain and employed as donors in combination with various acceptors to fabricate PSCs with enhanced efficiencies, manifested primarily with increased $\mathrm{V}_{\mathrm{oc}}$ and $\mathrm{J}_{\mathrm{sc}}$. Various ingeniously designed donor and acceptor units such as carbazole, fluorene, cyclopentadithiophenethiophene, benzo(1,2-b:4,5- $\left.b^{\prime}\right)$ dithiophene and benzothiadiazole, oxadiazole, diketopyrrolopyrrole, thieno(3,4-c)pyrole-4,6-dione, respectively, have been employed in an effort to improve solar cell performance [23-43]. To gain a deeper understanding on the influence of polymer properties on solar cell performance, a detailed characterization is required to unveil structure-property relationships, the nature of the excited states and possible limiting factors in their application in solar cells. Towards this goal, numerous studies have been published so far focusing on the use of ultrafast spectroscopic techniques for the investigation of other well known polymers like P3HT, PPV and PCDTBT [44-64].

Herein, we report in detail on the optoelectronic properties of a solution-processed polycarbazole-benzothiadiazole (CBZ-BT) based copolymer recently synthesized and computationally investigated by our group [65,66], its steady state and ultrafast photophysics upon blending with a fullerene PC70BM acceptor and its utilization as a donor in simple architecture polymer solar cells. A set of optical spectroscopy techniques such as stationary absorption and fluorescence as well as fs to ns time resolved and upconversion fluorescence spectroscopy have been used including polarization sensitive measurements. X-Ray and ultra-violet photoemission spectroscopy (XPS and UPS) measurements were also carried out in order to characterize the chemical elemental composition of the copolymer, the chemical and electronic state of its elements as well as its electronic structure (i.e. highest occupied molecular orbital (HOMO) and workfunction, respectively).

\section{Experimental section}

2.1 Optical spectroscopy (absorption/photoluminescence). Solution and thin film absorption spectra of CBZ-BT (on a glass substrate) were measured using a Jasco V$650 \mathrm{UV}-\mathrm{Vis}$ spectrophotometer while the fluorescence spectra were detected using a Fluoromax spectrometer (Horiba). The solid samples were placed on specific holders with an inclination angle of 10 degs. The measured spectra were appropriately corrected for the sensitivity of the detector. The fs-ps excited state dynamics were studied by means of a fs upconversion technique [67]. The excitation of the samples was realized at $400 \mathrm{~nm}$ i.e. at the second harmonic of the fundamental beam of a fs Ti:Sapphire laser. The excitation power was $\sim 2 \mathrm{~mW}$ ( $80 \mathrm{MHz}$ repetition frequency) and the pulse duration was $80 \mathrm{fs}$. The fluorescence of the samples was collected and focused on a $0.5 \mathrm{~mm} \mathrm{BBO}$ crystal together with the fundamental laser beam (optical 
gate) which has passed through a delay line generating an upconversion beam. This beam, generated in the BBO crystal, passed through appropriate filters and a monochromator and was finally detected by a photomultiplier. For anisotropy measurements, the polarization plane of the excitation beam was changed with respect to that of the optical gate by means of a Berek compensator. The fluorescence anisotropy was determined from the equation

$$
r(t)=\frac{I_{\text {par }}(t)-I_{\text {per }}(t)}{I_{\text {par }}(t)+2 I_{\text {per }}(t)}
$$

The time resolved anisotropy parameters were determined by fitting the difference factor $D(t)=I_{\text {par }}(t)-I_{\text {per }}(t)$ (difference fit). From equation (1) we obtain

$r(t)=\frac{I_{\text {par }}(t)-I_{\text {per }}(t)}{I_{\text {par }}(t)+2 * I_{\text {per }}(t)} \Rightarrow r(t)=\frac{I_{\text {par }}(t)-I_{\text {per }}(t)}{I_{\text {magic }}(t)} \Rightarrow I_{\text {par }}(t)-I_{\text {per }}(t)=r(t) \cdot I_{\text {magic }}$

Therefore, for obtaining the anisotropy parameters, the fitting function of the magic angle dynamics (with fixed parameters) was multiplied by a trial anisotropy fitting function (single or bi-exponential) and convoluted with the IRF. The parameters sought are those of $r(t)$ and were determined by fitting the final function to the $D(t)$ experimental results.

The ns fluorescence dynamics were studied by using a Time Correlated Single Photon Counting (TCSPC) system (Fluotime, Picoquant) equipped with a Microchannel Plate photomultiplier (MCP-PMT) [68]. A pulsed diode laser at $400 \mathrm{~nm}$ was used for the excitation of the samples. The IRF of this system was $\sim 80 \mathrm{ps}$. The light emitted by the samples was collected by a lens and passed through an analyzer and a monochromator before being detected by the MCP-PMT. For the ns anisotropy measurements the detection analyzer was set to horizontal and vertical orientation with respect to the polarization plane of the laser beam. The different response of the monochromator to the vertical and horizontal polarization was corrected by calculation of the G-factor. The ns anisotropy dynamics was analyzed by a tail fitting method.

2.2 Morphology, electronic structure and chemical state characterization. Surface morphology was investigated with a Veeco atomic force microscope (AFM), operated in tapping mode. XPS and UPS measurements were performed for samples without any further cleaning treatment prior to their introduction into an ultra-high vacuum chamber. For XPS, the $\mathrm{Mg} \mathrm{K \alpha}$ line at $1253.6 \mathrm{eV}(12 \mathrm{kV}$ with $20 \mathrm{~mA}$ anode current, not monochromatized) is used in combination with an analyser (Leybold EA-11) with a pass energy of $100 \mathrm{eV}$, giving a full width at half maximum (FWHM) of $1.3 \mathrm{eV}$ for the $\mathrm{Au} 4 \mathrm{f}_{7 / 2}$ peak. The analyzed area was approximately a $2 \times 5 \mathrm{~mm}^{2}$ rectangle, positioned near the geometric centre of each sample. XPS analysis was carried out at $0^{\circ}$ take-off angle (normal to the sample surface). In all XPS spectra, the binding energy (BE) of the predominant aliphatic contribution to the $\mathrm{C} 1 \mathrm{~s}$ peak at $284.8 \mathrm{eV}$ was used as a measured BE reference. For the UPS measurements, the He I excitation 
line $(21.2 \mathrm{eV})$ was used, and a negative bias of $12.23 \mathrm{~V}$ was applied to the specimen in order to separate the high binding energy cut-off from the analyser. The position of its HOMO level was extracted from the low binding energy (BE) (near-Fermi level) region while its workfunction was calculated from the high BE cutoff region.

2.3 Solar cell fabrication and characterization. CBZ-BT:PC70BM concentrations of $1: 2$ or $1: 4$ by weight in chloroform or 1,2 dichlorobenzene with a total concentration of $12.5 \mathrm{mg} / \mathrm{ml}$ (i.e: $2.5 \mathrm{mg}$ copolymer and 5 or $10 \mathrm{mg}$ PC70BM) were prepared for thin film fluorescence measurements and solar cell fabrication. Solutions were annealed and simultaneously stirred at $\sim 40^{\circ} \mathrm{C}$ for a few hours to ensure a homogeneous dispersion. Then, a few tens of $\mu$ ls of the solution was spin-coated at 600-1000 rpm for 40-60 sec (depending on the solvent used) on indium tin oxide (ITO) coated glass substrates (purchased from Sigma-Aldrich) that have been previously precoated with poly(3,4-ethylenedioxythiophene) polysterene sulfonate (PEDOT:PSS, purchased also from Sigma-Aldrich, spin coated at $4000 \mathrm{rpm}$ for $40 \mathrm{sec}$ and then annealed at $150^{\circ} \mathrm{C}$ for $30 \mathrm{~min}$ ). PEDOT:PSS was used as an anode interfacial layer to planarize ITO and improve hole extraction and device reproducibility. $\sim 100 \mathrm{~nm}$ thick blend films from chlorobenzene were solvent annealed for 30 minutes and then thermally annealed at $130^{\circ} \mathrm{C}$ for $15 \mathrm{~min}$ in air. Finally, an $\mathrm{Al}$ cathode was thermally evaporated through a shadow mask to complete device fabrication. Current density-voltage characteristics of the fabricated solar cells were measured with a Keithley 2400 source-measure unit in air immediately after fabrication. Cells were illuminated with a LCS-100 solar simulator (Newport Corporation) equipped with an AM 1.5G filter to simulate solar light illumination conditions with an intensity of $100 \mathrm{~mW} / \mathrm{cm}^{2}$, as was recorded with a calibrated power meter.

\section{Results and discussion}

3.1 Electronic properties of CBZ-BT films. The investigated poly(N-dodecyl-2,7carbazole-alt-benzothiadiazole) (CBZ-BT) copolymer synthesized via Suzuki coupling polymerization was optically and electronically characterized both in solution and thin films [65]. Its chemical structure is shown in Fig. 1.

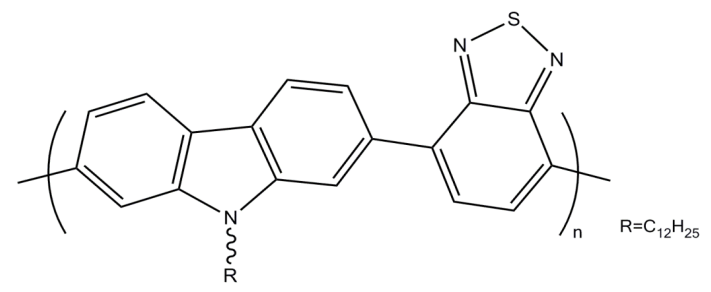

Fig. 1. Chemical structure of the poly(N-dodecyl-2,7-carbazole-alt-benzothiadiazole (CBZ-BT) copolymer. 
The copolymer has a low number average molecular weight $\left(\mathrm{M}_{\mathrm{n}}\right)$ of $1800 \mathrm{~g} / \mathrm{mol}$ and a weight average molecular weight $\left(\mathrm{M}_{\mathrm{w}}\right)$ of $2300 \mathrm{~g} / \mathrm{mol}$. It is soluble in common organic solvents such as THF, chloroform and chlorobenzene. Its electrochemical characterization using cyclic voltammetry revealed an ionization potential of $5.5 \mathrm{eV}$ (i.e oxidation potential of $0.7 \mathrm{~V} \mathrm{vs} . \mathrm{F}_{\mathrm{c}} / \mathrm{F}_{\mathrm{c}}{ }^{+}$potential at $4.8 \mathrm{~V}$ ) and an electron affinity of $3.0 \mathrm{eV}$ (i.e reduction potential of $1.8 \mathrm{~V}$ vs. $\mathrm{F}_{\mathrm{c}} / \mathrm{F}_{\mathrm{c}}{ }^{+}$) resulting in an electronic band gap of $2.5 \mathrm{eV}$.

In Figures 2a-d, the XPS spectra which contain valuable information concerning the chemical composition (stoichiometry), the spectral shape of the core-level orbitals and their binding energies (BEs) are presented.
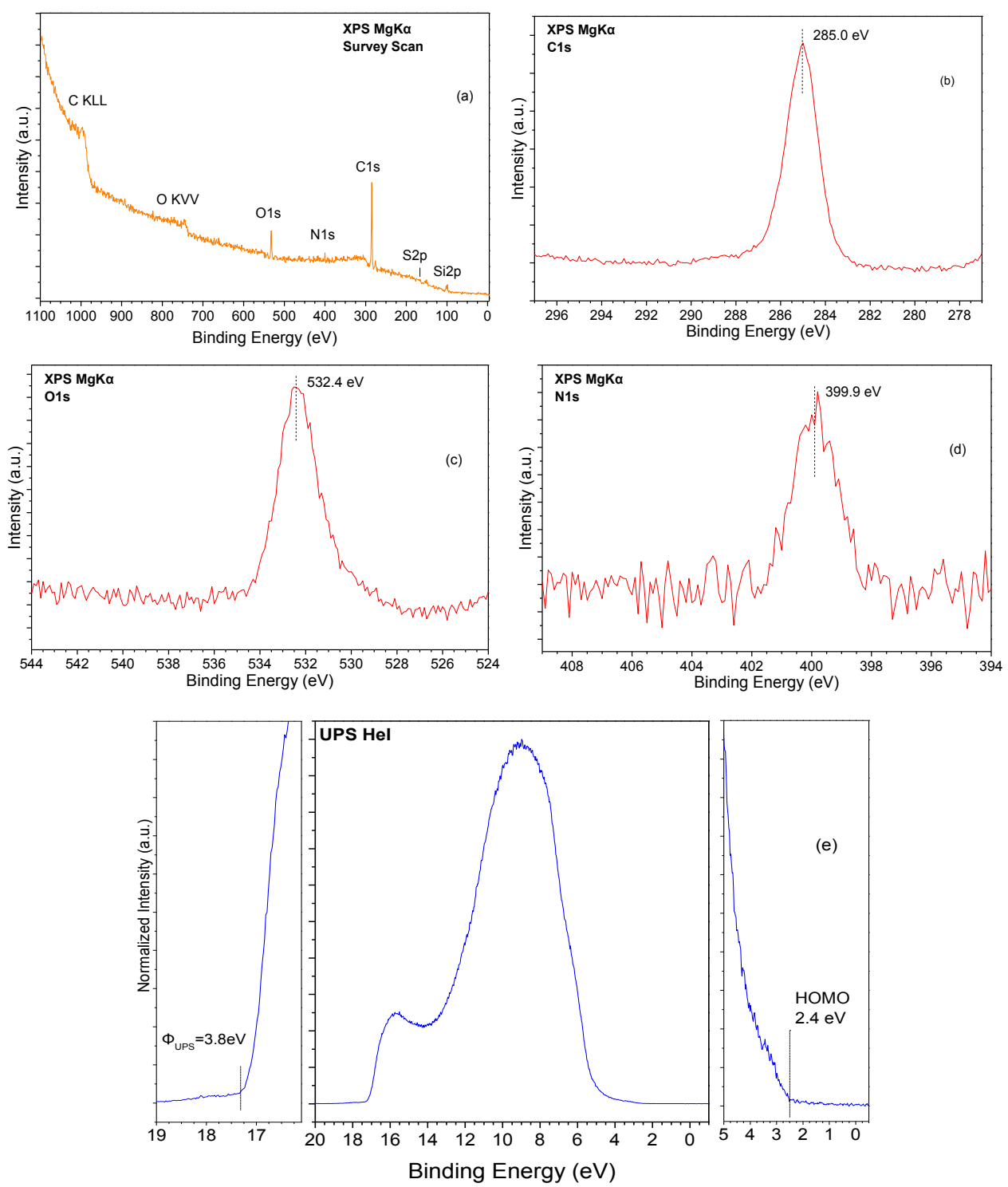

Fig. 2. (a)-(d) XPS core-level spectra of the CBZ-BT copolymer: a) Wide scan, b) $\mathrm{C} 1 \mathrm{~s}, \mathrm{c}) \mathrm{O} 1 \mathrm{~s}, \mathrm{~d}$ ) N1s spectra. (e) UPS spectrum of the CBZ-BT copolymer (the middle part depicts the full spectrum whereas the left and right part depict the high and low BE (near Fermi level) region, respectively). 
In Figure 2a the XPS wide scan can be seen whereas the atomic ratios supposing a 2.5 nm-thick carbon contamination layer on top of the surface $(\mathrm{C}: \mathrm{O}: \mathrm{N}: \mathrm{S}: \mathrm{Si}=1.00: 0.44: 0.11: 0.03: 0.02)$ may be extracted upon taking into account each core level's photoionization cross section to correct for their sensitivity. Figs. 2b$\mathrm{d}$ depict the $\mathrm{C} 1 \mathrm{~s}, \mathrm{O} 1 \mathrm{~s}$ and N1s core-level spectra with peaks at 285.0, 532.4 and 399.9 $\mathrm{eV}$, respectively. In Fig. 2e, the UPS spectrum of the CBZ-BT copolymer is presented (middle part of the Figure). On the right side of the Figure which depicts the spectrum at low BEs near the Fermi level, the highest occupied molecular orbital (HOMO) is found to be $2.4 \mathrm{eV}$ below the Fermi level. From the left side of the figure, the work function of the polymer can be calculated to be $3.8 \mathrm{eV}$ (from the onset at high BEs). This results in an ionization potential of $6.2 \mathrm{eV}$ and an electron affinity of $3.7 \mathrm{eV}$, upon substraction of its band gap $(2.5 \mathrm{eV})$ from the ionization potential value. The distinct difference $(\sim 0.7 \mathrm{eV})$ between the ionization potential values obtained by electrochemistry (in solution) and by UPS spectroscopy (in solid-state) may be indicative of strong polarization effects upon film self-organization. Furthermore, the local environment of the polymeric chains (solvent vs. thin film under high vacuum) may play a significant role in the determination of the ionization potential, as previously suggested [69].

3.2 Photophysical properties of CBZ-BT and CBZ-BT:PC ${ }_{70} B M$. Figure 3a shows the absorption and fluorescence spectra of CBZ-BT polymer in chloroform solution with a concentration of $0.027 \mathrm{mg} / \mathrm{ml}$. The photophysical parameters are summarized in Table 1. The polymer exhibits two absorption peaks in the visible and UV regions, as observed previously for other donor-acceptor copolymers, with no indication for ground state interaction [46, 70-73]. The high energy band located at $322 \mathrm{~nm}$ originates from the carbazole donor moiety while the lower energy band at $445 \mathrm{~nm}$ is assigned to the benzothiadiazole acceptor group [70,71]. Upon excitation, there is a significant charge displacement since the HOMO is extended over the whole polymeric chain i.e. both the carbazole and benzothiadiazole units while the LUMO is localized at the acceptor fragments i.e. benzothiadiazole [66]. Its fluorescence spectrum is broad and structureless and has a peak centered at $564 \mathrm{~nm}$. The peak position and shape of the spectrum is identical upon excitation at the high or low energy absorption peak pointing to emission that originates from excitation energy transfer between carbazole and benzothiadiazole. The only difference is that upon 322 $\mathrm{nm}$ the fluorescence intensity is 1.5 times higher (not shown), in agreement with the excitation spectra, being more intense at the high energy band. The agreement between the absorption and fluorescence excitation spectra indicates that energy is transferred very efficiently from carbazole to the benzothiadiazole group pointing to minimized energy losses. Finally the broad and structureless fluorescence spectrum indicates large torsional disorder in the excited state. If the fluorescence spectrum was structured and narrow displaying vibronic feature, it would point to a localized exciton to a state with weak torsional freedom (planarization). 
In films, the absorption peaks are red-shifted (Figure $3 \mathrm{~b}$ ) and the bands are broader. Specifically, the two absorption peaks are found at 338 and $475 \mathrm{~nm}$ (Table 1). The optical band gap is calculated $2.5 \mathrm{eV}$ by the absorption onset. As in the case of solutions, the fluorescence spectra in films were taken by exciting at both absorption peaks and the spectra were identical. Compared to the spectra of the solution, the fluorescence peak in films is red shifted to $588 \mathrm{~nm}$. Apart from the red-shift, there is not obvious broadening of the fluorescence spectrum of the films compared to that in solution. However, a small narrowing of the high energy part is observed possibly due to self absorption. The red-shift of both absorbance and fluorescence in solid-state films suggests increased intermolecular interactions (such as $\pi$-stacking).

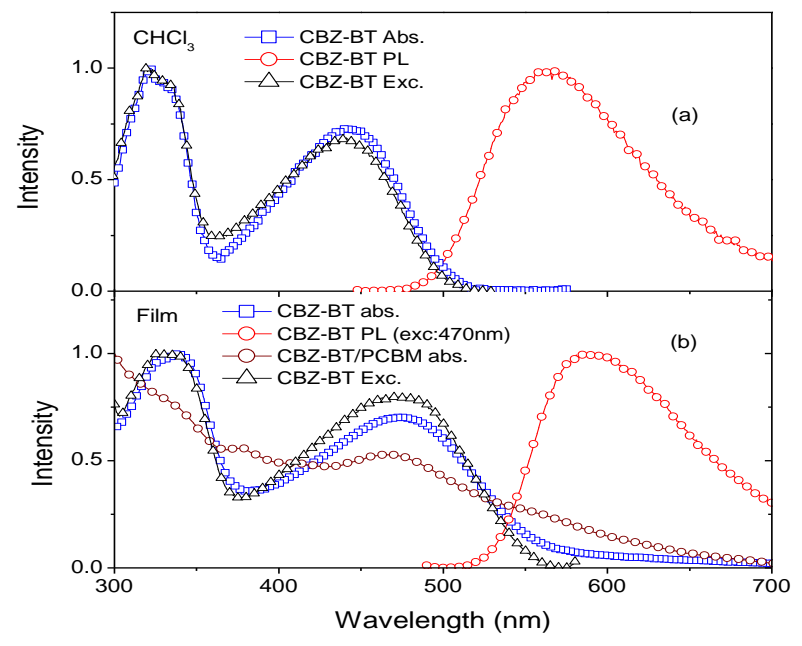

Fig. 3. Absorption, fluorescence and excitation spectra of CBZ-BT copolymer in (a) $\mathrm{CHCl}_{3}$ solutions and (b) neat film. In (b) the absorption spectrum of CBZBT:PC70BM blend film is also shown.

\begin{tabular}{llc}
\hline & $\lambda_{\text {Abs }}(\mathrm{nm})$ & $\lambda_{\text {Fluor }}(\mathrm{nm})$ \\
\hline $\mathrm{CBZ}-\mathrm{BT} / \mathrm{ChCl}_{3}$ & $322 / 445$ & 564 \\
$\mathrm{CBZ}-\mathrm{BT} / \mathrm{film}$ & $338 / 475$ & 588 \\
\hline
\end{tabular}

Table 1. Photophysical parameters of CBZ-BT in solution and thin film.

As in solutions, the excitation spectrum for CBZ-BT thin films is similar to the absorption one. Specifically, the peak positions remain unchanged. The only difference is that the relative intensity of the highest energy band (due to carbazole group) reduces vs. the intensity of the lowest energy one. This finding can be primarily ascribed to a part of the excitation energy provided to the carbazole moiety that is lost before energy transfer to the benzothiadiazole moiety by hopping to chain defects acting as quenching sites or by the formation of free polarons on separate chains which are non-fluorescent species [73].

In Figure 3b, the absorption spectrum of a CBZ-BT:PC70BM blend film (1:2 wt.\% ratio) is also shown. The absorption bands at $\sim 340$ and $470 \mathrm{~nm}$ are only slightly 
broader compared to those of CBZ-BT and exhibit a reduction in their intensity and the corresponding absorption coefficients. At $\sim 370 \mathrm{~nm}$, a new peak arises due to absorption from PC70BM. Also, a slight blue shift of the $470 \mathrm{~nm}$ CBZ-BT peak is observed upon blending with PC70BM which is probably due to reduced intermolecular interactions and a decrease of the interchain stacking in the presence of PC70BM. Again, no evidence for ground state interaction between CBZ-BT and PC70BM is observed. On the other hand, the fluorescence spectrum of CBZBT:PC70BM shows an almost complete quenching (more than $90 \%$ ) at a 50\% ratio (not shown), which is attributed to efficient exciton dissociation and photoinduced electron transfer from the excited state of the CBZ-BT donor to the PC70BM acceptor.

In order to shed light to the excited state dynamics of the copolymer and its blends with PC70BM, the fluorescence dynamics of CBZ-BT were first investigated in chloroform solutions to determine the fundamental decay properties of this polymer. The dynamics were studied upon excitation at $400 \mathrm{~nm}$ and detection at various wavelengths across the fluorescence spectrum. The excitation wavelength lies within the benzothiadiazole absorption band, but provides excess energy to the system and therefore relaxation phenomena such as thermalization of carriers and vibrational relaxation may be present. Figure 4a shows characteristic results at three decay wavelengths. The dynamics detected at high energies (short wavelengths) exhibit a fast decay while no rise mechanism is found. The absence of rise indicates that loss of the excess energy occurs faster than our instrument response function (IRF). At low energies (long wavelengths) the dynamics exhibit a rise followed by a slow decay. This behavior points to a transient red-shift of the fluorescence spectrum at short times in agreement with qualitatively similar results that have been found for other conjugated polymers in solutions $[46,47,74,75]$. In order to analyze the results, a global fitting method was performed based on a multiexponential function convoluted with the IRF. The obtained time constants were $\tau_{1}=0.54 \mathrm{ps}, \tau_{2}=4.9 \mathrm{ps}, \tau_{3}=46 \mathrm{ps}$ and $\tau_{4}=1.4 \mathrm{~ns}$ (Table 2). These time constants are in great similarity with those found for PCDTBT in chlorobenzene solution using the same experimental method [46]. The pre-exponential factors are shown in Figure $4 \mathrm{~b}$ and Table 2 together with the average lifetimes calculated by $\tau_{\text {aver }}=\frac{\sum_{i=1}^{4} A_{i} \tau_{i}}{\sum_{i=1}^{4} A_{i}}$. 

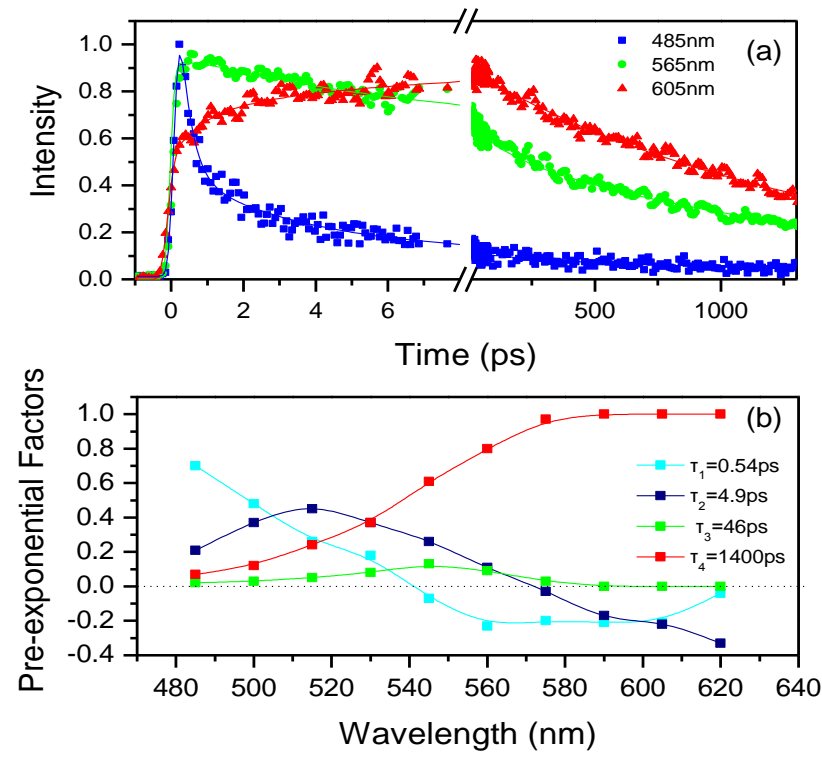

Fig. 4. (a) Excited state dynamics for CBZ-BT in chloroform solutions at three different detection wavelengths measured by FU, (b) pre-exponential amplitudes as a function of emission wavelength obtained after a global fitting analysis with a multiexponential function.

The time constants found via a multiexponential fitting may represent an average time originated by different competing mechanisms taking place on a similar timescale. Therefore, imposing a specific physical mechanism to each time constant may be complicated and risky. In our case, the two fast time constants $\left(\tau_{1}\right.$ and $\left.\tau_{2}\right)$ of the order of 0.5-5 ps are responsible for the spectral relaxation as they have positive amplitudes at short wavelengths and negative at long ones pointing to a decay and rise respectively.

\begin{tabular}{cccccccccc}
\hline$\lambda_{\text {det }}(\mathrm{nm})$ & $\mathrm{A}_{1}$ & $\tau_{1}(\mathrm{ps})$ & $\mathrm{A}_{2}$ & $\tau_{2}(\mathrm{ps})$ & $\mathrm{A}_{3}$ & $\tau_{3}(\mathrm{ps})$ & $\mathrm{A}_{4}$ & $\tau_{4}(\mathrm{ps})$ & $\tau_{\text {aver }}(\mathrm{ps})$ \\
\hline 485 & 0.70 & 0.54 & 0.21 & 4.9 & 0.02 & 46 & 0.07 & 1400 & 100 \\
500 & 0.48 & & 0.37 & & 0.03 & & 0.12 & & 171 \\
515 & 0.26 & & 0.45 & & 0.05 & & 0.24 & & 340 \\
530 & 0.18 & & 0.37 & & 0.08 & & 0.37 & & 520 \\
545 & -0.07 & & 0.26 & & 0.13 & & 0.61 & & 860 \\
560 & -0.23 & & 0.11 & & 0.09 & 0.80 & & 1120 \\
575 & -0.20 & & -0.03 & & 0.03 & & 0.97 & & 1360 \\
590 & -0.21 & & -0.17 & & 0 & & 1 & & 1400 \\
605 & -0.21 & & -0.22 & & 0 & & 1 & & 1400 \\
620 & -0.04 & & -0.33 & & 0 & & 1 & & 1400 \\
\hline
\end{tabular}

Table 2. Fitting results of the FU fluorescence dynamics for CBZ-BT in chloroform solution obtained after a global analysis. The excitation wavelength was $400 \mathrm{~nm}$.

Mechanisms such as vibrational cooling, conformational changes of the polymer backbone and inter- or intra-chain energy transfer of excitons could contribute to the spectral relaxation. However, vibrational cooling occurs on a 100 fs timescale [46] 
and therefore it is most possible that conformational changes and transfer of excitons are the origin of the spectral relaxation on the timescale of 0.5-5 ps observed here. On the other hand, spectral relaxation due to solvation cannot be ruled out since chloroform has been found to exhibit solvation times of $\sim 4$ ps [76]. Besides, exciton self localization has been reported to occur on a $<100 \mathrm{fs}$ timescale and most probably it is not observed through our magic angle dynamics [46]. However, the processes taking place within our IRF could affect the polarization sensitive experiments (vide infra). Finally, $\tau_{3}$ has positive amplitudes at all emission wavelengths and therefore corresponds to a decay procedure, maybe from an unrelaxed non-localized exciton. This is the reason why its pre-exponential factors are small. The longest time constant $\left(\tau_{4}=1.4 \mathrm{~ns}\right)$ suffers from increased uncertainty due to the temporal limit of the fs upconversion technique and it is due to a population decay from the relaxed excited state. Since the fluorescence spectrum of CBZ-BT is broad and unstructured, various emitting conformers exist. This means that the $1.4 \mathrm{~ns}$ lifetime is most probably an average lifetime of the emitting species and it can be analyzed in more details by means of ns spectroscopy.

Therefore, in order to better analyze the dynamics on long timescales, a TCSPC technique was used and the long decay of CBZ-BT in chloroform solution is shown in Figure 5. Fitting of the TCSPC decay curve revealed three decay mechanisms with lifetimes (normalized amplitudes) $\tau_{1}=0.65 \mathrm{~ns}(0.37), \tau_{2}=2.5 \mathrm{~ns}(0.24)$ and $\tau_{3}=4.3 \mathrm{~ns}$ (0.39) with $\chi^{2}$ equal to 1.01 , while fitting with a bi-exponential function gave a less satisfactory $\chi^{2}$ parameter higher than 1.15 . The observation of three decay mechanisms reveals the existence of various emitting species as mentioned before. In order to correlate the fluorescence dynamics detected on a short (upconversion) and long (TCSPC) timescale, the amplitude averaged lifetime of the two first mechanisms ( $0.65 \mathrm{~ns}$ and $2.5 \mathrm{~ns}$ ) obtained by TCSPC was calculated and found $1.38 \mathrm{~ns}$. This value is very close to the $1.4 \mathrm{~ns}$ found by the fs upconversion measurements. The longer 4.3 ns component was not used for the calculation of the average lifetime and comparison with the upconversion results because this is much longer than the upper temporal limit (1.5 ns) of the fs technique.

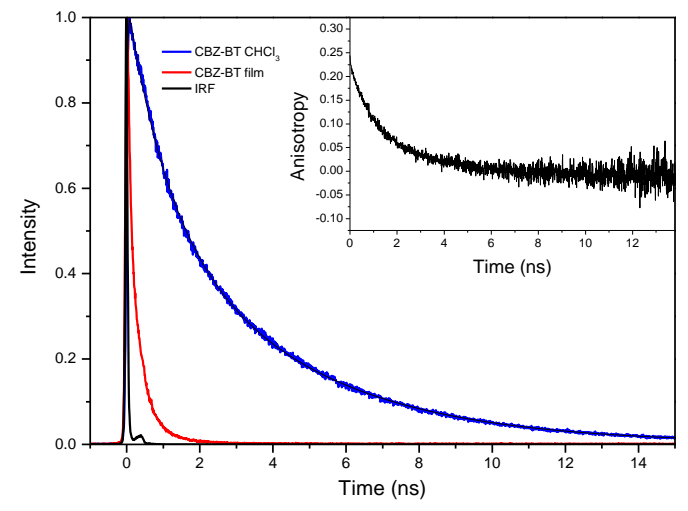


Fig. 5. Fluorescence dynamics in the ns timescale of CBZ-BT in chloroform solutions and deposited as a neat film on glass obtained by TCSPC. The inset shows the ns anisotropy dynamics of CBZ-BT in chloroform.

Figures $6 \mathrm{a}$ and $\mathrm{b}$ show the fluorescence dynamics polarized parallel and vertical to the polarization plane of the excitation beam for two emission wavelengths i.e. 500 and $565 \mathrm{~nm}$, while Figure 6c presents the corresponding anisotropy $r(t)$ of CBZ-BT in chloroform solutions. In general, anisotropy dynamics is a valuable experimental tool to investigate energy transfer/migration phenomena as these lead to depolarization of fluorescence and thus to a decay of anisotropy [46,47,77-83]. The initial anisotropy, $r_{0}$, at $565 \mathrm{~nm}$ is 0.25 i.e. lower than the upper limit of 0.4 which is predicted for parallel absorption and emission transition dipoles. The fact that the initial anisotropy is lower than the theoretical upper limit could indicate non-parallel absorption and emission dipoles but it also indicates significant depolarization within the IRF of our system. In that case, ultrafast mechanisms such as exciton self localization and energy vibrational relaxation may contribute to emission depolarization. Fitting of the anisotropy decay on the ps timescale, gave a time constant of $43 \mathrm{ps}$, i.e. very close to the 46 ps time constant found in magic angle dynamics. This means that rotation of the emission dipole takes place on this timescale. After a few tens of ps, the anisotropy reaches a limiting value of $\sim 0.2$ as shown at the inset of Figure 6c, indicating an angle of $\sim 35^{\circ}$ between the absorption and emission dipole moments. Since, excitation by means of the fs pulses is realized at the lowest energy band (i.e. the benzothiadiazole absorption band), this dipole rotation involves energy transfer steps between various benzothiadiazole units and does not involve the carbazole $\rightarrow$ benzothiadiazole energy transfer. The drop of anisotropy within $200 \mathrm{ps}$ is small, pointing to a small amount of hopping steps. 

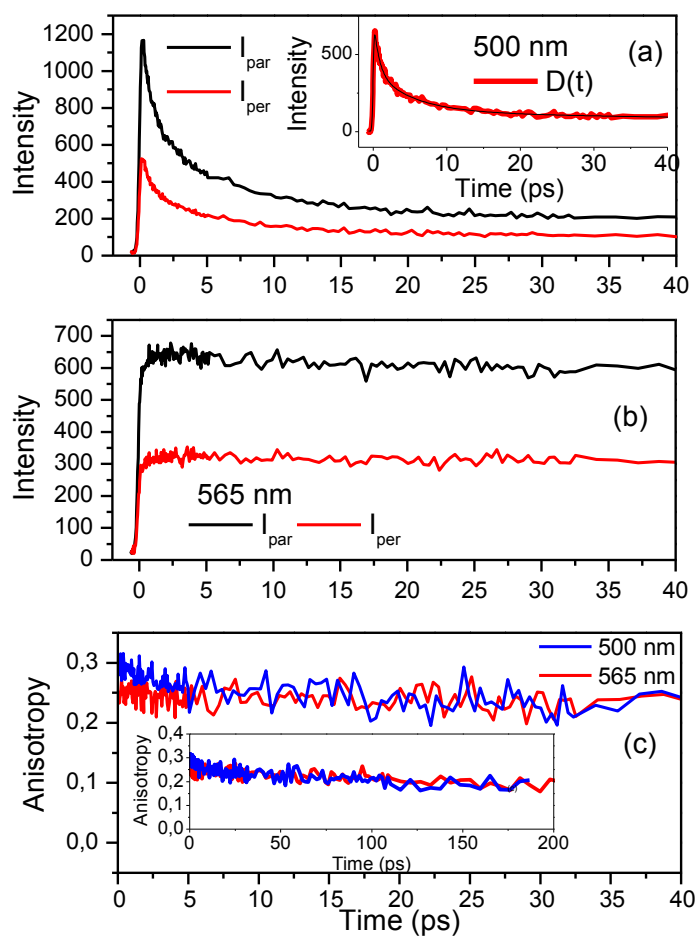

Fig. 6. Fluorescence dynamics polarized parallel and perpendicular with respect to the polarization plane of the laser beam for CBZ-BT in chloroform detected at (a) 500nm and (b) $565 \mathrm{~nm}$. (c) The corresponding anisotropy dynamics at 500 and $565 \mathrm{~nm}$. The inset in (a) shows the difference factor $D(t)=I_{p a r}(t)-I_{p e r}(t)$ used for determining the anisotropy decay parameters. The inset in (c) shows the anisotropy dynamics on a 0 200 ps timescale.

However, the faster time constants observed in magic angle dynamics because of exciton transfer, leading to spectral relaxation, are not observed in the anisotropy dynamics detected at $565 \mathrm{~nm}$ possibly because at this wavelength the fluorescence intensity is mainly due to an already relaxed state that is generated after energy migration. In order to probe higher excited states i.e. non-relaxed states, the anisotropy dynamics was studied at $500 \mathrm{~nm}$ i.e. at the blue edge of the fluorescence spectrum. The initial anisotropy, $r_{0}$, found at $500 \mathrm{~nm}$ is 0.3 i.e. higher than that found at $565 \mathrm{~nm}$ while a fast decay component is also observed which was not found at 565 $\mathrm{nm}$. After fitting of the difference factor $D(t)=I_{p a r}(t)-I_{p e r}(t)$, at $500 \mathrm{~nm}$, the fast decay time was found $3.4 \mathrm{ps}$ which is in very good agreement with the average of the fast decay times found under magic angle detection meaning that exciton migration leads to emission depolarization. This depolarization takes place after electronic dephasing has taken place and is due to a hopping excitation energy transfer. Next, the anisotropy at $500 \mathrm{~nm}$ decays with a $\sim 45 \mathrm{ps}$ component with small amplitude as at 565 $\mathrm{nm}$ i.e apart from the $3.4 \mathrm{ps}$ time constant found at $500 \mathrm{~nm}$, the anisotropy at the two detection wavelengths decays on the same manner after the first 20 ps. So, in our case the fluorescence depolarization is due to a bi-phasic homotransfer among the benzothiadiazole units. Note that this type of hopping among iso-energetic species affects the transition dipole orientation but not the emission spectrum. On the ns 
timescale, a long component of $1.48 \mathrm{~ns}$ which is due to the very slow rotation of the polymer chains is found by TCSPC (inset of Figure 5).

Next, the dynamics for CBZ-BT thin film on glass substrates was studied as shown in Figure 7a. The dynamics were detected again at various wavelengths across the fluorescence spectrum. Care was taken to minimize exciton-exciton annihilation which occurs at high excitation powers. In that case, two excitons combine to form a higher energy one causing a quenching of fluorescence and acceleration of the decay dynamics. Various excitation powers were used and measurements showed that the decays become slower as the excitation power decreases due to vanishing contribution of annihilation while this retardation saturates at low energies. Therefore our measurements were performed with the smallest excitation power possible where annihilation is considered absent. A similar global fitting analysis, as in the case of solutions, was used and the time constants were found $\tau_{1}=0.8 \mathrm{ps}, \tau_{2}=3.0 \mathrm{ps}, \tau_{3}=22 \mathrm{ps}$ and $\tau_{4}=160$ ps (Table 3). The fastest time constant has amplitudes that become negative at long wavelengths and is therefore responsible for a gradual shift of the fluorescence spectrum to lower energies (Figure $7 \mathrm{~b}$ and Table 3). This time constant is larger than the corresponding one observed for solutions ( $0.54 \mathrm{ps})$. This fact, together with the absence of a longer spectral re-organization time constant is due to the reduced conformational freedom of CBZ-BT in film and absence of solvation. If conformational and torsional changes were important, then spectral relaxation in films within the few ps timescale would be slower than that in solutions. The other three time constants have positive amplitudes meaning that they represent decay mechanisms. These three time constants are found faster in films than in solutions implying that they are affected by interchain interactions. $\tau_{2}$ and $\tau_{3}$ could potentially represent the decay of unrelaxed species while $\tau_{4}$ represents the decay of the relaxed state. $\tau_{4}$ is much smaller that the corresponding time in solutions pointing to a significant quenching due to interchain effects. Such a reduced lifetime is due to increased non-radiative transitions $[84,85]$. Measurements via the TCSPC method revealed two decay mechanisms with lifetimes (amplitudes) equal to $\tau_{1}=0.12 \mathrm{~ns}(0.76)$ and $\tau_{2}=0.42 \mathrm{~ns}(0.24)$ (Figure 5). The average of these lifetimes is 0.178 ns, i.e. close to the value found by fs upconversion. 

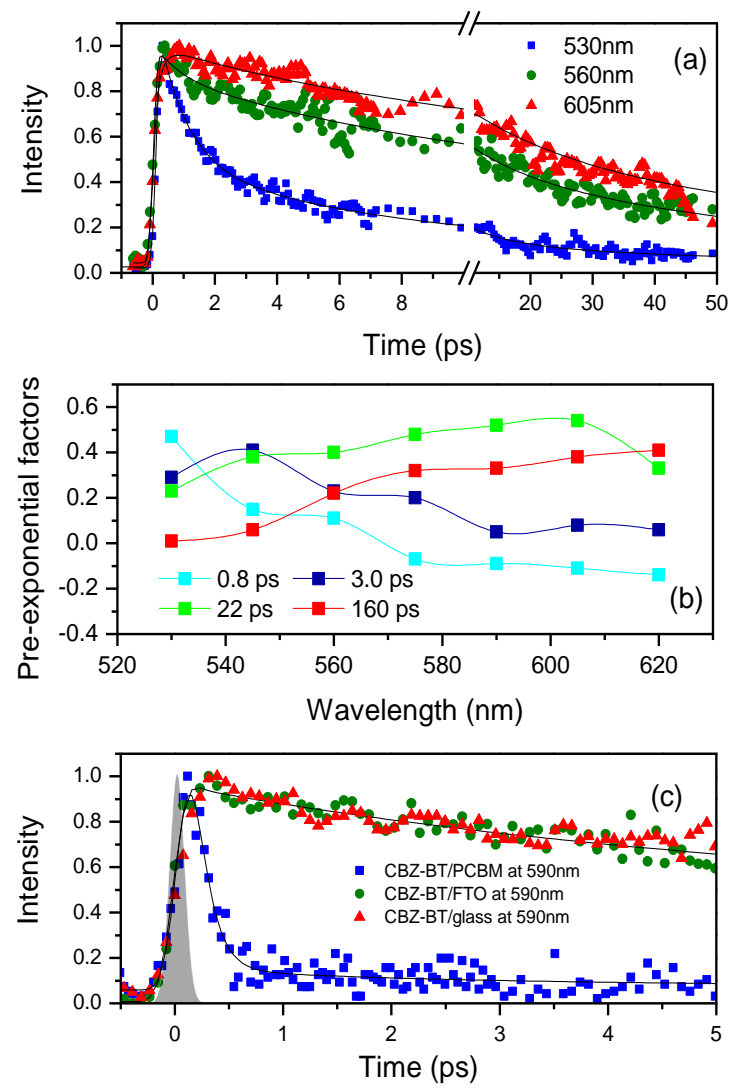

Fig. 7. a) Excited state dynamics of a CBZ-BT film at three detection wavelengths. (b) pre-exponential amplitudes as a function of emission wavelength obtained after a global fitting analysis with a multiexponential function, (c) Excited state dynamics of the same film on glass and FTO and of a CBZ-BT:PC70BM (1:2 wt\%) blend on FTO.

\begin{tabular}{cccccccccc}
\hline$\lambda_{\text {det }}(\mathrm{nm})$ & $\mathrm{A}_{1}$ & $\tau_{1}(\mathrm{ps})$ & $\mathrm{A}_{2}$ & $\tau_{2}(\mathrm{ps})$ & $\mathrm{A}_{3}$ & $\tau_{3}(\mathrm{ps})$ & $\mathrm{A}_{4}$ & $\tau_{4}(\mathrm{ps})$ & $\tau_{\text {aver }}(\mathrm{ps})$ \\
\hline 530 & 0.47 & 0.8 & 0.29 & 3.0 & 0.23 & 22 & 0.01 & 160 & 7.9 \\
545 & 0.15 & & 0.45 & & 0.38 & & 0.06 & & 19 \\
560 & 0.11 & & 0.23 & & 0.40 & & 0.22 & & 44 \\
575 & -0.07 & & 0.2 & & 0.48 & & 0.32 & & 62 \\
590 & -0.09 & & 0.05 & & 0.52 & & 0.33 & & 65 \\
605 & -0.11 & & 0.08 & & 0.54 & & 0.38 & & 73 \\
620 & -0.14 & & 0.06 & & 0.33 & & 0.41 & & 77 \\
\hline
\end{tabular}

Table 3. Fitting results of the FU fluorescence dynamics for CBZ-BT deposited as neat film on glass obtained after a global analysis.

Besides, magic angle dynamics, the time dependent anisotropy was also studied in the polymeric neat films at the peak of the fluorescence spectra and the results are shown in Figure 8. First, the initial anisotropy is close to that found at the emission peak of the polymeric solution $(565 \mathrm{~nm})$ meaning that the initial $(<100 \mathrm{fs})$ coherent depolarization is mainly of intrachain character. Fitting of the difference factor (inset in Figure 8a) led to a fast decay time of 0.7 ps and a second one of 7 ps. The former is within the spectral relaxation timescale observed under magic angle conditions. However, in films, the anisotropy decays much faster than in solutions due to the 
much increased possibility of inter-chain energy transfer because of the much closer proximity of the polymeric chains. This leads to an increased rotation of the transmission dipole and finally to a loss of anisotropy. The limiting anisotropy (at 40 ps) for CBZ-BT in films, being smaller than that in solutions, is also an indication of increased disorder compared to solutions.

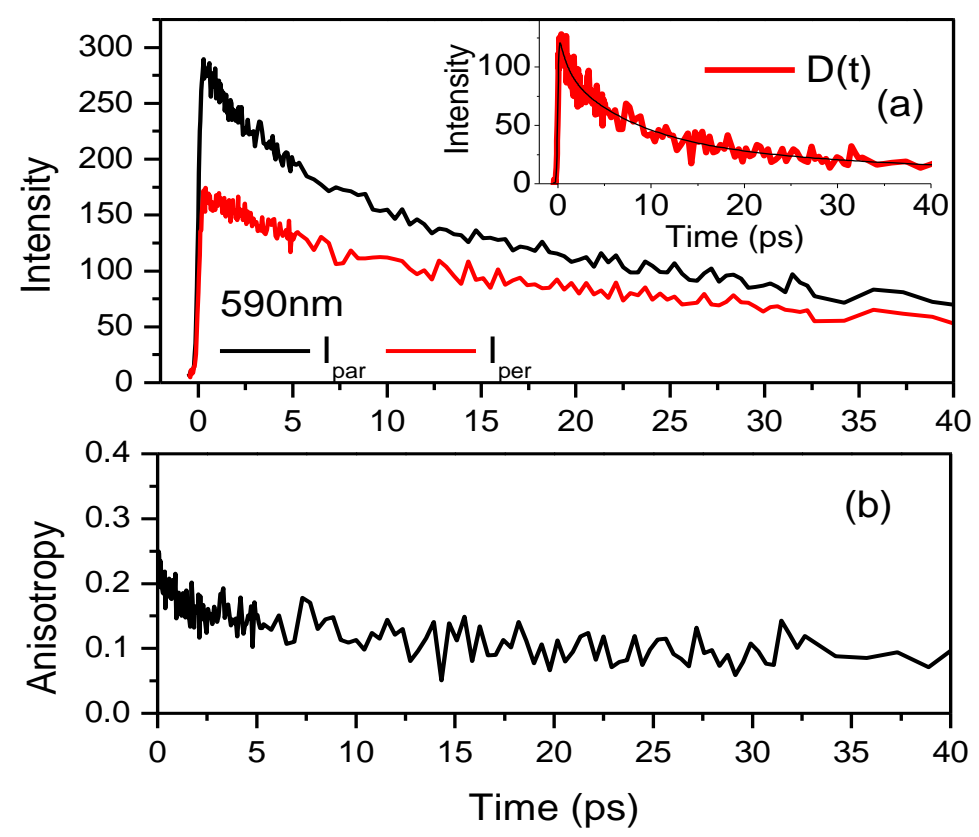

Fig. 8. (a) Fluorescence dynamics polarized parallel and perpendicular with respect to the polarization plane of the laser beam for CBZ-BT neat film detected at $590 \mathrm{~nm}$. (b) The corresponding anisotropy dynamics. The inset in (a) shows the difference factor $D(t)=I_{\text {par }}(t)-I_{\text {per }}(t)$ used for determining the anisotropy decay parameters.

Finally, CBZ-BT was studied in blend films with PC70BM deposited on fluorine doped tin oxide (FTO) substrates. For comparison, a neat CBZ-BT film deposited on FTO was also studied. The results are shown in Figure $7 \mathrm{c}$. In this figure, the corresponding results for CBZ-BT on glass are presented as a reference. It is obvious that the decay of CBZ-BT on FTO is identical to that in glass. On the other hand, the decay of CBZ-BT/PC70BM film exhibits an ultrafast decay of $\sim 150$ fs with pronounced contribution while only $\sim 5 \%$ of the initial intensity survives after $5 \mathrm{ps}$ (the IRF is also shown). This indicates highly efficient emission quenching due to the exciton dissociation and charge transfer from the polymer to PC70BM $[45,86,87]$, in excellent agreement with the steady state fluorescence measurements. This process is obviously highly desirable towards high solar cell efficiency and suggests that this copolymer could be an effective donor in polymer solar cells with PC70BM or other fullerene acceptors. 
3.3 Polymer solar cell characteristics. The potential of using CBZ-BT as a polymer donor in solar energy conversion was next investigated. Polymer solar cells from a chloroform CBZ-BT:PC70BM (1:2 or 1:4 wt.\%) solution were fabricated and electrically characterized. A simple architecture ITO/PEDOT:PSS/CBZ$\mathrm{BT}: \mathrm{PC} 70 \mathrm{BM} / \mathrm{Al}$ was used for the fabricated solar cells. Optimum performance was demonstrated for a CBZ-BT:PC70BM 1:4 wt.\% ratio either in chloroform or in 1,2 dichlorobenzene. Only a minor influence of the solvent or additives such as 1,8 diiodooctane (DIO) on solar cell performance was noted, possibly as a result of its amorphous nature (vide infra). Solar cells with this donor:acceptor ratio showed a relatively high $\mathrm{V}_{\mathrm{oc}}$ of $0.83 \mathrm{~V}$, a $\mathrm{J}_{\mathrm{sc}}$ of $4.3 \mathrm{~mA} / \mathrm{cm}^{2}$, and a $\mathrm{FF}$ at 0.48 resulting in a relatively low power conversion efficiency (PCE) of 1.7\%. Cells with a 1:2 wt.\% ratio showed a $\mathrm{V}_{\mathrm{oc}}$ of $0.85 \mathrm{~V}, \mathrm{a} \mathrm{J}_{\mathrm{sc}}$ of $4.7 \mathrm{~mA} / \mathrm{cm}^{2}$, a FF at 0.37 resulting in a similar PCE of $1.5 \%$. The main difference upon increasing the PC70BM:CBZ-BT ratio is the significantly increased FF with only a small influence on $V_{o c}$ and $J_{s c}$. The increased FF suggests more balanced charge transport and reduced nongeminate recombination, probably caused by an improved degree of intermixing and, thus, an increased number of pathways for charges to reach the electrodes. Despite the relatively high $\mathrm{V}_{\mathrm{oc}}$ obtained that is directly attributed to the large ionization potential of the CBZ-BT copolymer, the low $\mathrm{J}_{\mathrm{sc}}$ suggests a limited charge collection efficiency. Although the significant difference between the LUMO of CBZ-BT and PC70BM that amounts $\Delta \mathrm{E}_{\mathrm{LUMO}} \sim 0.6 \mathrm{eV}$ should provide the necessary driving force for charge separation, the low $\mathrm{J}_{\mathrm{sc}}$ may be a direct result of the relatively small value of the change in the Gibbs free energy $\Delta \mathrm{G}$ between the excited and the charge separated state defined by the relation $\Delta \mathrm{G}=\mathrm{IP}_{\mathrm{D}}-\mathrm{EA}_{\mathrm{A}}-\mathrm{E}_{\text {exciton}}$, where $\mathrm{IP}_{\mathrm{D}}$ is the donor ionization potential $(6.2 \mathrm{eV})$, $\mathrm{EA}_{\mathrm{A}}$ is the acceptor electron affinity $(4.3 \mathrm{eV})$ and $\mathrm{E}_{\text {exciton }}$ is the photogenerated donor exciton energy (2.1 eV, as calculated from the emission spectrum peak energy). Herein, $\Delta \mathrm{G}=-0.2 \mathrm{eV}$ which is lower than the optimal $\Delta \mathrm{G}=-0.3-0.5 \mathrm{eV}$ for PSCs [88], potentially leading to a decreased charge-separation rate and, thus, an overall lower charge collection. In Figure 9, the J-V characteristics of the fabricated PSCs in the dark and under illumination are depicted. The dark J-V characteristics demonstrate a good diode behavior (i.e. low leakage current and distinct turn-on voltage of $\sim 0.8 \mathrm{~V}$ ).
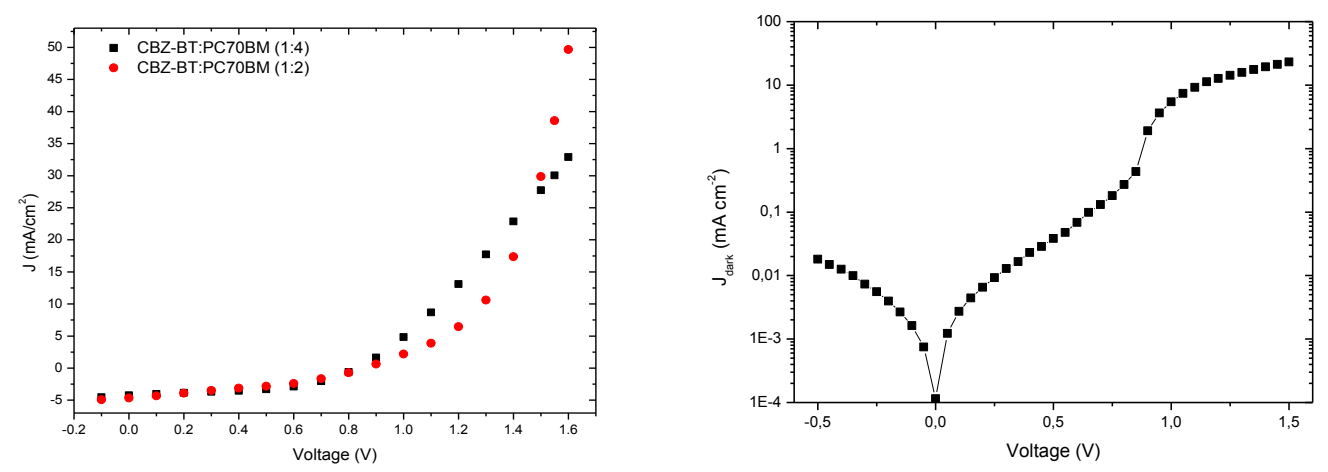
Fig. 9. (a) $J-V$ characteristics for ITO/PEDOT:PSS/CBZ-BT:PC70BM (1:4 or 1:2 wt.\% ratio)/Al PSCs. (b) The dark J-V characteristics of the CBZ-BT:PC70BM (1:4 wt.\%) based cell.

XRD spectra of CBZ-BT and its blends with PC70BM showed no diffraction peaks (not shown), even after annealing up to $150^{\circ} \mathrm{C}$, indicating that the copolymer is amorphous, as also verified previously by differential scanning calorimetry analyses [65]. Finally, the surface morphology of the CBZ-BT:PC70BM (1:2 wt.\% ratio) blend films was investigated by atomic force microscopy (AFM) in order to unveil its possible influence on the PSC performance. As shown in Figure 10, blend films were relatively homogeneous with a root mean square (RMS) roughness value of $0.62 \mathrm{~nm}$. Films exhibited small nanoscale phase separation with intermixed domains in the range of 50-100 $\mathrm{nm}$, which is generally favorable for relatively effective charge generation as suggested by the fluorescence measurements.

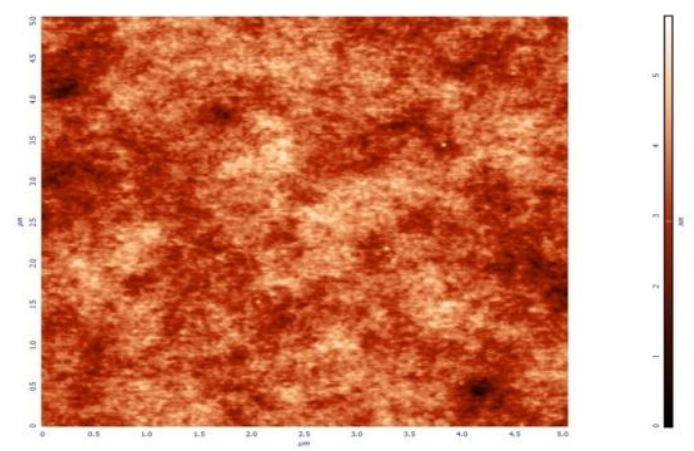

Fig. 10. $5 \times 5 \mu \mathrm{m}^{2}$ AFM topographic image of CBZ-BT:PC70BM blend film with a 1:2 weight ratio.

\section{Conclusions}

In summary, a donor-acceptor carbazole-benzothiadiazole copolymer (CBZ-BT) was investigated in depth with regard to its optoelectronic properties and utilized as an electron donor in polymer solar cells in conjunction with PC70BM. The XPS characterization revealed the atomic ratio on the polymer surface while UPS characterization resulted in a solid-state ionization potential of $6.2 \mathrm{eV}$ and a film workfunction of $3.8 \mathrm{eV}$. CBZ-BT photophysical characterization revealed a broad and structureless fluorescence spectrum due to torsional disorder at the excited state, originating from intramolecular energy transfer between carbazole and benzothiadiazole. Besides, a transient spectral relaxation within few ps was observed due to conformational changes of the polymer chains and downhill relaxation of excitons. This spectral relaxation was faster in films. Time resolved anisotropy measurements revealed a faster depolarization in films due to increased disorder. The femtosecond time-resolved fluorescence studies of the CBZ-BT:PC70BM blend revealed an ultrafast photoinduced electron transfer taking place in less than $150 \mathrm{fs}$ from the copolymer to PC70BM supporting the steady state fluorescence picture that 
exhibited almost complete quenching upon its blending with PC70BM. Relatively high open circuit voltage $(\sim 0.85 \mathrm{~V})$ but low power conversion efficiency $(1.7 \%)$ CBZ-BT:PC70BM (1:2 wt\% ratio) polymer solar cells were demonstrated in a single layer device architecture. This study provides particular insights in the ultrafast excited state dynamics of a carbazole-benzothiadiazole based copolymer both in solution and film and unveils its potential for applications in solar energy harvesting. Further improvements in solar cell efficiency can be anticipated upon using higher molecular weight carbazole-benzothiadiazole copolymers and employing more advanced architectures.

\section{Acknowledgments}

This work was supported by Grant E.028 from the Research Committee of the University of Patras (Programme K. Karatheodori awarded to Prof. M. Fakis). Polymer synthesis was performed within the framework of the Equipex ELORPrintTec ANR-10-EQPX-28-01 and the LCPO/Arkema/ANR INDUSTRIAL CHAIR "HOMERIC" ANR-13-CHIN-0002-01 within the grant agreement number AC-2013-365. The authors are also grateful to the Region Aquitaine, the CNRS, Bordeaux INP and the University of Bordeaux.

\section{References}

[1] N. Sariciftci, L. Smilowitz, A. J. Heeger, Photoinduced Electron-transfer From a Conducting Polymer to Buckminsterfullerene, Science 258 (1992) 1474-1476.

[2] N. S. Sariciftci, D. Brown, C. Zhang, Semiconducting Polymer-buckminsterfullerene Heterojunctions-diodes, Photodiodes and Photovoltaic Cells, Appl. Phys. Lett. 62 (1993) 585-587.

[3] R. Sondergaard, M. Hösel, D. Angmo, T. T. Larsen-Olsen, F. C. Krebs, Roll-to-roll Fabrication of Polymer Solar Cells, Mater. Today 15 (2012) 36-49.

[4] I. Raptis, D. Velessiotis, M. Vasilopoulou, P. Argitis, Development Mechanism Study by Dissolution Monitoring of Positive Methacrylate Photoresists, Microelectron. Eng. 53 (2000) 489-492.

[5] G. Yu, J. Gao, J. C. Hummelen, F. Wudl, A. J. Heeger, Polymer Photovoltaic Cells Enhanced Efficiencies Via a Network of Internal Donor-Acceptor Heterojunctions, Science 270 (1995) 1789-1791.

[6] G. Li, V. Shrotiya, J. Yuang, Y. Yao, T. Moriarti, K. Emery, Y. Yang, High-efficiency Solution Processable Polymer Photovoltaic Cells by Self Organisation of Polymer Blends, Nat. Mater 4 (2005) 864-868.

[7] W. Ma, C. Yang, X. Z. Gong, K. Lee, A. J. Heeger, Thermally Stable, Efficient Polymer Solar Cells With Nanoscale Control of the Interpenetrating Network Morphology, Adv. Funct. Mater. 15 (2005) 1617-1622. 
[8] J. Y. Kim, S. H. Kim, H. H. Lee, K. Lee, W. Ma, X. Gong, A. J. Heeger, New Architecture for High Efficiency Polymer Photovoltaic Cells Using Solution-based Titanium Oxide as Optical Spacer. Adv. Mater. 18 (2006) 572-576.

[9] K. Lee, W. L. Ma, C. J. Brabec, J. Yuen, J. S. Moss, J. Y. Kim, G. C. Bazan, A. J. Heeger, Processing Additives for Improved Efficiency from Bulk-heterojunction Solar Cells, J. Am. Chem.Soc. 130 (2008) 3619-3623.

[10] Y. Liu, J. Zhao, Z. Li, C. Mu, W. Ma, H. Hu, K. Jiang, H. Lin, H. Ade, H. Yan, Aggregation and Morphology Control Enables Multiple Cases of High Efficiency Polymer Solar Cells, Nat. Commun. 5 (2014) 1-8.

[11] A. R. M. Yusoff, D. Kim, H. P. Kim, F. K. Schneider, W. J. DaSilva, J. A. Jang, High Efficiency Solution Processed Polymer Inverted Triple Junction Solar Cell Exhibiting a Power Conversion Efficiency of 11.83\%, Energy Environ. Sci. 8 (2015) 303-316.

[12] S. A. Gevorgyan, M. V. Madsen, H. F. Dam, M. Jorgensen, C. J. Fell, K. F. Anderson, B. C. Duck, A. Mescheloff, E. A. Katz, A. Elschner, R. Roesch, H. Hoppe, M. Hermenau, M. Riede, F. C Krebs Interlaboratory Outdoor Stability Studies of Flexible Roll-to-roll Coated Organic Photovoltaic Modules: Stability Over 10,000 h, Sol. Energy Mater. Sol. Cells 116 (2013) 187-196.

[13] M. Vasilopoulou, D. G. Georgiadou, A. Soultati, N. Boukos, S. Gardelis, L. C. Palilis, M. Fakis, G. Skoulatakis, S. Kennou, M. Botzakaki, S. Georga, C. A. Krontiras, F. Auras, D. Fattakhova-Rohlfing, T. Bein, T. A. Papadopoulos, D. Davazoglou, P. Argitis, Atomic-LayerDeposited Aluminum and Zirconium Oxides for Surface Passivation of $\mathrm{TiO} 2$ in HighEfficiency Organic Photovoltaics, Adv. Energy Mater. 4 (2014) 1400214.

[14] M. Vasilopoulou, A. M. Douvas, D. G. Georgiadou, V. Constantoudis, D. Davazoglou, S. Kennou, L. C. Palilis, D. Daphnomili, A. G. Coutsolelos, P. Argitis, Large Work Function Shift of Organic Semiconductors Inducing Enhanced Interfacial Electron Transfer in Organic Optoelectronics Enabled by Porphyrin Aggregated Nanostructures, Nano Res. 7 (2014) 679693.

[15] M. Vasilopoulou, E. Polydorou, A. M. Douvas, L. C. Palilis, S. Kennou, P. Argitis, Annealing-free Highly Crystalline Solution-processed Molecular Transition Metal Oxides as Charge Transport and Recombination Layers for Efficient and Stable Single-junction and Tandem Polymer Solar Cells, Energy Environ. Sci. 8 (2015) 2448-2463.

[16] L. Nian, W. Zhang, N. Zhu, L. Liu, Z. Xie, H. Wu, F. Wu, F. Wurthner, Y. Ma, Photoconductive Cathode Interlayer for Highly Efficient Inverted Polymer Solar Cells, J. Am. Chem. Soc. 137 (2015) 6995-6998.

[17] W. Li, L. Ye, S. Li, H.Yao, H. Ade, J. Hou, A High-Efficiency Organic Solar Cell Enabled by the Strong Intramolecular Electron Push-Pull Effect of the Nonfullerene Acceptor, Adv. Mater. (2018) 1707170.

[18] W. Zhao, S. Li, H. Yao, S. Zhang, Y. Zhang, B. Yang, J. Hou, Molecular Optimization Enables over 13\% Efficiency in Organic Solar Cells, J. Am. Chem. Soc. 139 (2017) 71487151.

[19] X. Xu, T. Yu, Z. Bi, W. Ma, Y. Li, Q. Peng, Realizing Over 13\% Efficiency in GreenSolvent-Processed Nonfullerene Organic Solar Cells Enabled by 1,3,4-Thiadiazole-Based Wide-Bandgap Copolymers, Adv. Mater. (2017) 1703973.

[20] J. Zhang, L. Zhu, Z. Wei, Toward Over 15\% Power Conversion Efficiency for Organic Solar Cells: Current Status and Perspectives, Small Methods (2017) 1700258.

[21] E. Bundgaard, F. C. Krebs, Low Band Gap Polymers for Organic Photovoltaics. Sol. Energy Mater. Sol. Cells, 91 (2007) 954-985. 
[22] R. Kroon, M. Lenes, J. C. Hummelen, P. W. M. Blom, B. De Boer, Small Band Gap Polymers for Organic Solar Cells (Polymer Material Development in the last 5 Years), Polym. Rev. 48 (2008) 531-582.

[23] R. A. M. Verstrijden, M .M. Wienk, R. A. J. Janssen, Copolymers of Diketopyrrolopyrrole and Thienothiophene for Photovoltaic Cells, J. Mater. Chem. 21 (2011) 9224-9231.

[24] P. Sonar, E. Williams, W. P. Singh, S. Manzhos, A. Dodabalapur, Benzothiadiazole End Capped Donor-Acceptor Based Small Molecule for Organic Electronics, Phys. Chem. Chem. Phys. 15 (2013) 17064-17069.

[25] L. Biniek, B. C. Schroeder, C. B. Nielsen, I. McCulloch, Recent Advances in High Mobility Donor-acceptor Semiconducting Polymers, J. Mater. Chem. 22 (2012) 14803-14813. [26] S. Qu, H. Tian, Diketopyrrolopyrrole (DPP)-based Materials for Organic Photovoltaics, Chem. Commun. 48 (2012) 3039-3051.

[27] P. Sonar, G. M. Ng, T. T. Lin, A. Dodapalapur, Z. -K. Chen, Solution Processable Low Bandgap Diketopyrrolopyrrole (DPP) Based Derivatives: Novel Acceptors for Organic Solar Cells,. J. Mat. Chem. 20 (2010) 3626-3636.

[28] C. Duan, A. Furlan, J. J. Van Franeker, R. E. M. Willems, M. M. Wienk, R. A. J. Janssen, Wide-Bandgap Benzodithiophene-Benzothiadiazole Copolymers for Highly Efficient Multijunction Polymer Solar Cells, Adv. Mater. 27 (2015) 4461-4468.

[29] K. A. Mazzio, M. J. Yuan, K. Okamoto, C. K. Luscombe, Oligoselenophene Derivatives Functionalized with a Diketopyrrolopyrrole Core for Molecular Bulk Heterojunction Solar Cells, ACS Appl. Mater. Interfaces 3 (2011) 271-278.

[30] I. McCulloch, R. S. Ashraf, L. Biniek, H. Bronstein, C. Combe, J. E. Donaghey, D. I. James, C. B. Nielsen, B. C. Schroeder, Design of Semiconducting Indacenodithiophene Polymers for High Performance Transistors and Solar Cells, Acc. Chem. Res. 45 (2012) 714722.

[31] V. Anand, E. Ramachandran, R. Dhamodharan, Conjugated Polymers with Carbazole, Fluorene, and Ethylene Dioxythiophene in the Main Chain and a Pendant Cyano Group: Synthesis, Photophysical, and Electrochemical Studies, J. Polym. Sci. Part A Polym. Chem. 54 (2016) 2774-2784.

[32] A. A. B. Alghamdi, A. Imragaa, E. S. Abdel-Halim, A. Iraqi, Synthesis and Characterization of Novel Thiophene and Carbazole-based Polymers - Optical and Electrochemical Characterization, Intern. J. Electrochem. Sci. 11 (2016) 5111-5127.

[33] M. Liu, Y. Wang, Z. Zhang, J. Li, Y. Liu, H. Tan, M. Ni, G. Lei, M. Zhu, W. Zhu, Significantly Improved Photovoltaic Performances of the Dithiophene-benzothiadiazole-altfluorene Copolymers by Incorporating Carbazole Units in Fluorene Moiety, J. Polym. Sci. Part A Polym. Chem. 49 (2011) 3874-3881.

[34] Y. Fu, H. Cha, G. -Y. Lee, B. J. Moon, C. E. Park, T. Park, 3,6-Carbazole Incorporated Into Poly(9,9-dioctylfluorene-alt-(bisthienyl)benzothiadiazole)s Improving the Power Conversion Efficiency, Macromolecules 45 (2012) 3004-3009.

[35] W. Li, Q. Li, S. Liu, C. Duan, L. Ying, F. Huang, Y. Cao, Synthesis of Twodimensional $\pi$-conjugated Polymers Pendent with Benzothiadiazole and Naphtho(1,2-c:5,6c)bis(1,2,5)thiadiazole Moieties for Polymer Solar Cells, Sci. China Chem. 58 (2015) 257266. 
[36] J. Kim, Y. S. Kwon, W. S. Shin, S. -J Moon, T. Park, Carbazole-Based Copolymers: Effects of Conjugation Breaks and Steric Hindrance, Macromolecules 44 (2011) 1909-1919.

[37] N. Blouin, A. Michaud, D. Gendron, S. Wakim, E. Blair, R. Neagu-Plesu, M. Belletete, G. Durocher, Y. Tao, M. Leclerc, Toward a Rational Design of Poly(2,7-carbazole) Derivatives for Solar Cells, J. Am. Chem. Soc. 130 (2008) 732-742.

[38] J. Kim, M. H. Yun, P. Anant, S. Cho, J. Jacob, J. Y. Kim, Y. Yang, Copolymers Comprising 2,7-Carbazole and Bis-benzothiadiazole Units for Bulk-Heterojunction Solar Cells, Chem. A Europ. J. 17 (2011) 14681-14688.

[39] H. Ito, T. Iwata, S. Watanabe, S. Kuroda, Balanced Ambipolar Transport of the Composite Film of a Carbazole-Benzothiadiazole Copolymer with a Fullerene derivative, Appl. Phys. Expr. 6 (2013) 051601.

[40] M. F. G. Klein, F. M. Pasker, S. Kowarik, D. Landerer, M. Pfaff, M. Isen, D. Gerthsen, U. Lemmer, S. Hoger, A. Colsmann, Carbazole-Phenylbenzotriazole Copolymers as Absorber Material In Organic Solar Cells, Macromolecules 46 (2013) 3870-3878.

[41] J. S. Park, S. -H. Jin, Y. -S. Gal, J. H. Lee, J. W. Lee, Synthesis and Characterization of Carbazole-based Copolymers Containing Benzothiadiazole Derivative for Polymer LightEmitting Diodes, Mol. Cryst. and Liq. Cryst. 567 (2011) 567, 102-109.

[42] C. Du, W. Li, C. Li, Z. Bo, Ethynylene-Containing Donor-Acceptor Alternating Conjugated Polymers: Synthesis and Photovoltaic Properties, J. Polym. Sci. Part A Polym. Chem. 51 (2013) 383-393.

[43] R. Qin, J. Yang, P. Li, Q. Wu, Y. Zhou, H. Luo, F. Chang, Structure Property Relationship for Carbazole and Benzothiadiazole Based Conjugated Polymers, Sol. Energy Mater. Sol. Cells 145 (2016) 412-417.

[44] I. Hwang, S. Beaupré, M. Leclerc, G. D. Scholes, Ultrafast Relaxation of Charge-transfer Excitons in Low-bandgap Conjugated Copolymers, Chem. Sci. 3 (2012) 2270-2277.

[45] Y. Xie, Y. Li, L. Xiao, Q. Qiao, R. Dhakal, Z. Zhang, Q. Gong, D. Galipeau. X. Yan, Femtosecond Time-Resolved Fluorescence Study of P3HT/PC70BM Blend Films, J. Phys. Chem. C 114 (2010) 14590-14600.

[46] N. Banerji, S. Cowan, M. Leclerc, E. Vauthey, A. J. Heeger, Exciton Formation, Relaxation, and Decay in PCDTBT, J. Am. Chem. Soc. 132 (2010) 17459-17470.

[47] N. Banerji, S. Cowan, E. Vauthey, A. J. Heeger, Ultrafast Relaxation of the Poly(3hexylthiophene) Emission Spectrum, J. Phys. Chem. C. 115 (2011) 9726-9739.

[48] B. R. Gao, H. Y. Wang, H. Wang, Z. Y. Yang, L. Wang, Y. Jiang, Y. W. Hao, Q. D. Chen. H. B. Sun, Investigation of Polaron Pair Dynamics in Poly(3-Hexylthiophene) Film by Time Resolved Spectroscopy, IEEE J. Quantum Electron. 48 (2012) 425-432.

[49] J. Jiang, A. Alsam, S. Wang, S. M. Aly, Z. Pan, O. F. Mohammed, K. S. Schanze, Effect of Conjugation Length on Photoinduced Charge Transfer in $\pi$-Conjugated Oligomer-Acceptor Dyads, J. Phys. Chem. A 121 (2017) 4891-4901.

[50] B. G. A. L. Borges, A. G. Veiga, L. Tzounis, A. Laskarakis, S. Logothetidis, M. L M. Rocco, Molecular Orientation and Ultrafast Charge Transfer Dynamics Studies on the P3HT:PCBM Blend, J. Phys. Chem. C 120 (2016) 25078-25082.

[51] J. Men, H. Ting, Y. Li, W. Wang, G. Gao, L. Xiao, Z. Chen, S. Wang, Q. Gong, Static and ultrafast time-resolved fluorescent anisotropy in oriented Poly(3-hexylthiophene) films, Chem. Phys. Lett. 609 (2014) 33-36.

[52] P. C. Tapping, T. W. Kee, Optical Pumping of Poly(3-hexylthiophene) Singlet Excitons Induces Charge Carrier Generation, J. Phys. Chem. Lett. 5 (2014) 1040-1047.

[53] M. C. Heiber, A. Dhinojwala, Estimating the Magnitude of Exciton Delocalization in Regioregular P3HT, J. Phys. Chem. C 117 (2013) 21627-21634. 
[54] S. N. Clafton, D. M. Huang, W. R. Massey, T. W. Kee, Femtosecond Dynamics of Excitons and Hole-Polarons in Composite P3HT/PCBM Nanoparticles, J. Phys. Chem. B 117 (2013) 4626-4633.

[55] W. Zhang, R. Hu, D. Li, M. M. Huo, X. C. Ai, J. P. Zhang, Primary Dynamics of Exciton and Charge Photogeneration in Solvent Vapor Annealed P3HT/PCBM Films, J. Phys. Chem. C 116 (2012) 4298-4310.

[56] E. Busby, E. C. Carroll, E. M. Chinn, L. Chang, A. J. Moulé, D. S. Larsen, Excited-State Self-Trapping and Ground-State Relaxation Dynamics in Poly(3-hexylthiophene) Resolved with Broadband Pump-Dump-Probe Spectroscopy, J. Phys. Chem. Lett. 2 (2011) 2764-2769.

[57] J. Guo, H. Ohkita, H. Benten, S. Ito, Near-IR Femtosecond Transient Absorption Spectroscopy of Ultrafast Polaron and Triplet Exciton Formation in Polythiophene Films with Different Regioregularities, J. Am. Chem. Soc. 131 (2009) 16869-16880.

[58] L. W. Barbour, R. D. Pensack, M. Hegadorn, S. Arzhantsev, J. B. Asbury, Excitation Transport and Charge Separation in an Organic Photovoltaic Material: Watching Excitations Diffuse to Interfaces, J. Phys. Chem. C. 112 (2008) 3926-3934.

[59] J. G. Müller, J. M. Lupton, J. Feldmann, U. Lemmer, M. C. Scharber, N. S. Sariciftci, C. J. Brabec, U. Scherf, Ultrafast Dynamics of Charge Carrier Photogeneration and Geminate Recombination in Conjugated Polymer:fullerene Solar Cells, Phys. Rev. B 72 (2005) 195208.

[60] K. M. Gaab, C. J. Bardeen, Anomalous Exciton Diffusion in the Conjugated Polymer MEH-PPV Measured Using a Three-Pulse Pump-Dump-Probe Anisotropy Experiment, J. Phys. Chem. A 108 (2004) 10801-10806.

[61] K. M. Gaab, C. J. Bardeen, Wavelength and Temperature Dependence of the Femtosecond Pump-Probe Anisotropies in the Conjugated Polymer MEH-PPV: Implications for Energy-Transfer Dynamics, J. Phys. Chem. B 108 (2004) 4619-4626.

[62] C. Yang, M. Wohlgenannt, Z. V. Vardeny, W. J. Blau, A. B. Dalton, R. Baughman, A . A. Zakhidov, Photoinduced Charge Transfer in Poly(p-phenylene vinylene) Derivatives and Carbon Nanotube/C60 Composites, Physica B 338 (2003) 366-369.

[63] M. Scarongella, A. Laktionov, U. Rothlisberger, N. Banerji, Charge Transfer Relaxation in Donor-Acceptor Type Conjugated Materials, J. Mater. Chem. C 1 (2013) 2308-2319.

[64] E. Collado-Fregoso, S. N. Hood, S. Shoaee, B. C. Schroeder, I. McCulloch, I. Kassal, D. Neher, J. R. Durrant, Intercalated vs Nonintercalated Morphologies in Donor-Acceptor Bulk Heterojunction Solar Cells: PBTTT:Fullerene Charge Generation and Recombination Revisited, J. Phys. Chem. Lett. 8 (2017) 4061-4068.

[65] J. Oriou, F. Ng, G. Hadziioannou, C. Brochon, E. Cloutet, Synthesis and StructureProperty Relationship of Carbazole-alt-benzothiadiazole Copolymers, J. Polym. Sci. Part A Polym. Chem. 53 (2015) 2059-2068.

[66] A. Fradon, E. Cloutet, G. Hadziioannou, C. Brochon, F. Castet, Optical Properties of Donor-Acceptor Conjugated Copolymers: A Computational Study, Chem. Phys. Lett. 678 (2017) 9-16.

[67] M. Fakis, E. Stathatos, G. Tsigaridas, V. Giannetas, P. Persephonis, Femtosecond Decay and Electron Transfer Dynamics of the Organic Sensitizer D149 and Photovoltaic Performance in Quasi-Solid State Dye-Sensitized Solar Cells, J. Phys. Chem. C 115 (2011) 13429-13437.

[68] N. Droseros, K. Seintis, M. Fakis, S. Gardelis, A. Nassiopoulou, Steady State and Time Resolved Photoluminescence Properties of CuInS2/ZnS Quantum Dots in Solutions and in Solid Films, J. Luminesc. 167 (2015) 333-338. 
[69] R. Rybakiewicz, P. Gawrys, D. Tsikritzis, K. Emmanouil, S. Kennou, M. Zagorska, Pron, A. Electronic Properties of Semiconducting Naphthalene Bisimide Derivatives Ultraviolet Photoelectron Spectroscopy Versus Electrochemistry, Electrochimica Acta 96 (2013) 13-17.

[70] J. Kim, M. H. Yun, P. Anant, S. Cho, J. Jacob, J. Y. Kim, C. Yang, Copolymers Comprising 2,7-Carbazole and Bis-benzothiadiazole Units for Bulk-Heterojunction Solar Cells, Chem. Eur. J. 17 ( 2011) 14681-14688.

[71] C. Du, W. Li, C. Li, Z. Bo, Ethynylene-containing Donor-Acceptor Alternating Conjugated Polymers: Synthesis and Photovoltaic Properties, J. Polym. Sci. A 51 (2013) 383393.

[72] J. S. Park, S. H. Jin, Y. S. Gal, J. H. Lee, J. W. Lee, Synthesis and Characterization of Carbazole-based Copolymers Containing Benzothiadiazole Derivative for Polymer LightEmitting Diodes, Mol. Cryst. Liq. Cryst. 576 (2012) 102-109.

[73] M. Westerling, H. Aarnio, R. Österbacka, H. Stubb, S. M. King, A. P. Monkman,M. R. Andersson, K. Jespersen, T. Kesti, A. Yartsev, V. Sundström, Photoexcitation dynamics in an alternating polyfluorene copolymer, Phys. Rev. B 75 (2007) 224-306.

[74] B. Ferreira, P. F. Da Silva, J. S. S. De Melo, J. Pina, A. Maçanita, Excited-State Dynamics and Self-Organization of Poly(3-hexylthiophene) (P3HT) in Solution and Thin Films. J. Phys, Chem. B 116 (2012) 2347-2355.

[75] N. P. Wells, B. W. Boudouris, M. A. Hillmyer, D.A. Blank, Intramolecular Exciton Relaxation and Migration Dynamics in Poly(3-hexylthiophene), J. Phys. Chem. C 111 (2007) 15404-15414.

[76] M. L. Horng, J. A. Gardecki, A. Papazyan, M. Maroncelli, Subpicosecond Measurements of Polar Solvation Dynamics: Coumarin 153 Revisited, J. Phys. Chem., 99 (1995) 1731117337.

[77] B. Keller, A. McLean, B. G. Kim, K. Chung, J. Kim, T. Goodson III, Ultrafast Spectroscopic Study of Donor-Acceptor Benzodithiophene Light Harvesting Organic Conjugated Polymers, J. Phys. Chem. C 120 (2016) 9088-9096.

[78] S. A. Schmid, K. H. Yim, M. H. Chang, Z. Zheng, W. T. S. Huck, R. H. Friend, J. S. Kim, L. M. Herz, Polarization anisotropy dynamics for thin films of a conjugated polymer aligned by nanoimprinting, Phys. Rev. B 77 (2008) 115-338.

[79] P. C. Tapping, S. N. Clafton, K. N. Schwarz, T. W. Kee, D. M. Huang, Molecular-Level Details of Morphology-Dependent Exciton Migration in Poly(3-hexylthiophene) Nanostructures, J. Phys. Chem. C 119 (2015) 7047-7059.

[80] M. M. -L Grage, P. W. Wood, A. Ruseckas, T. Pullerits, W. Mitchell, P. L. Burn, I. D. W. Samuel, V. Sundström, Conformational Disorder and Energy Migration in MEH-PPV with partially broken conjugation, J. Chem. Phys, 118 (2003) 7644-7650.

[81] S. Westenhoff, C. Daniel, R. H. Friend, C. Silva, V. Sundström, A. Yartsev, Exciton Migration in a Polythiophene: Probing the Spatial and Energy Domain by Line-dipole Förster-type Energy Transfer, J. Chem. Phys. 122 (2005) 094903-1-094903-8.

[82] I. Hwang, G. D. Scholes, Electronic Energy Transfer and Quantum-Coherence in $\pi$ Conjugated Polymers, Chem. Mater. 23 (2011) 610-620.

[83] S. A. Schmid, R. Abbel, A. P. H. Schenning, E. W. Meijer, R. P. Sijbesma, L. M. Herz, Analyzing the Molecular Weight Distribution in Supramolecular Polymers, J. Am. Chem. Soc. 131 (2009) 17696-17704.

[84] S. Cook, A. Furube, R. Katoh, Analysis of the Excited States of Regioregular Polythiophene P3HT, Energy Environ. Sci. 1 (2008) 294-299. 
[85] S. Trotzky, T. Hoyer, W. Tuszynski, C. Lienau, J. Parisi, Femtosecond Up-Conversion Technique for Probing the Charge Transfer in a P3HT:PC70BM Blend Via Photoluminescence Quenching, J. Phys. D: Appl. Phys. 42 (2009) 055-105.

[86] J. Piris, T. E. Dykstra, A. A. Bakulin, P. H. M. Van Loosdrecht, W. Knulst, M. T. Trinh, J. M. Schins, L. D. A. Siebbeles, Photogeneration and Ultrafast Dynamics of Excitons and Charges in P3HT/PC70BM Blends, J. Phys. Chem. C. 113 (2009) 14500-14506.

[87] H. Wang, H. -Y. Wang, B. -R. Gao, L. Wang, Z. -Y. Yang, X. -B. Du, X. Q. -D. Chen, J. -F. Song, H. -B. Sun, Exciton Diffusion and Charge Transfer Dynamics in Nano Phaseseparated P3HT/PC70BM Blend Films, Nanoscale 3 (2011) 2280-2285.

[88] D. C. Coffey, B. W. Larson, A. W. Hains, J. B. Whitaker, N. Kopidakis, O. V. Boltalina, S. H. Strauss, G. Rumbles, An Optimal Driving Force for Converting Excitons into Free Carriers in Excitonic Solar Cells, J. Phys. Chem. C. 116 (2012) 8916-8923. 